\title{
Analisis Sistem Pengangkutan Sampah di Wilayah Surabaya Utara
}

\author{
Rizka Andriani Mahmudah dan Welly Herumurti \\ Jurusan Teknik Lingkungan, Fakultas Teknik Sipil dan Perencanaan, Institut Teknologi Sepuluh Nopember (ITS) \\ Jl. Arief Rahman Hakim, Surabaya 60111 Indonesia \\ e-mail: herumurti@enviro.its.ac.id
}

\begin{abstract}
Abstrak - Surabaya Utara merupakan wilayah dengan kepadatan penduduk tertinggi kedua setelah wilayah Surabaya Pusat. Hal ini mengakibatkan besarnya laju timbulan sampah di Surabaya Utara yang harus dikelola. Analisis sistem pengangkutan Sampah di Surabaya Utara bertujuan untuk memberikan informasi tentang kondisi eksisting sistem pengangkutan sampah yang meliputi rute dan jarak pengangkutan sampah, kecepatan pengangkutan sampah, waktu pengangkutan sampah dan jumlah timbulan sampah yang terangkut dari TPS Surabaya Utara menuju ke TPA. Pengangkutan di Surabaya Utara yang dianalisis terdiri dari pengangkutan dengan Arm Roll Truckdan Dump Truck. Jarak pengangkutan sampah di Surabaya Utara dipengaruhi oleh jumlah ritasi dan jarak TPS yang dilayani menuju ke TPA. Jumlah ritasi pengangkutan sampah pada truk DKP rata - rata yaitu 2 rit/hari dan pada truk rekanan yaitu 3 rit/hari. Alternatif jalan (jalan tol atau jalan biasa) tidak memberikan pengaruh yang signifikan terhadap waktu pengangkutan sampah dikarenakan kecepatan rata - rata pengangkutan sampah yang digunakan adalah sama. Faktor offroute pengangkutan sampah di Surabaya $<0,15$ yaitu 0,07 , namun sisa waktu kerja yang cukup banyak memunkinkan dilakukan penambahan jumlah ritasi. Densitas rata - rata sampah di truk pengangkutan sampah di Surabaya Utara adalah $229,29 \mathrm{~kg} / \mathrm{m}^{3}$ untuk kontainer masih ada tutup dan $361,85 \mathrm{~kg} / \mathrm{m}^{3}$ untuk kontainer yang sudah lepas tutupnya.
\end{abstract}

Kata Kunci-Jarak pengangkutan, kecepatan pengangkutan, rute, Timbulan sampah, waktu pengangkutan

\section{PENDAHULUAN}

$\mathrm{P}$ ENINGKATAN laju timbulan sampah di negara berkembang dipengaruhi oleh jumlah populasi, industrialisasi, urbanisasi, dan pertumbuhan ekonomi [1]. Sampah domestik menjadi masalah yang serius di kota besar dengan kepadatan populasi yang tinggi seperti Kota Surabaya [2]. Pelaksanaan penanganan sampah di wilayah Kota Surabaya terbagi menjadi 5 (lima) zona. Zona tersebut yaitu Surabaya Pusat, Surabaya Timur, Surabaya Selatan, Surabaya Utara dan Surabaya Barat [3].

Pengelolaan sampah terdiri dari upaya pengurangan sampah dan upaya penanganan sampah. Upaya pengurangan sampah terdiri dari pembatasan timbulan sampah, pendauran ulang sampah, dan pemanfaatan kembali sampah. Upaya upaya penanganan sampah meliputi pemilahan, pengumpulan, pengangkutan, pengolahan, dan pemrosesan akhir [4]. Tiga elemen penting dalam perwujudan integrasi keberlanjutan sistem pengelolaan sampah [5]. Pertama, komponen fisik dari penanganan sampah yaitu dari timbulan sampah, pengumpulan, hingga ke TPA. Kedua, pelaku atau stakeholder yang terlibat. Ketiga, aspek - aspek dari strategi yang meliputi politik, kelembagaan, sosial, finansial, dan teknis. Aspek finansial atau biaya operasi dalam pengangkutan sampah meliputi biaya pemeliharaan kendaraan, tenaga kerja dan bahan bakar [6].

Analisis sistem pengangkutan sampah dilakukan di wilayah studi Surabaya Utara. Kepadatan penduduk Surabaya Utara sebesar 165 jiwa/ha dan memiliki tingkat kepadatan terbesar kedua setelah Surabaya Pusat [7]. Surabaya Utara memiliki 30 TPS yang dilayani oleh truk pengangkutan sampah. umur teknis kendaraan pengangkutan sampah adalah 5 sampai 7 tahun [8]. Sementara itu, beberapa truk Arm Roll yang melayani Surabaya Utara mempunyai umur yang lebih dari 15 tahun [9]. Analisis sistem pengangkutan sampah bertujuan untuk menentukan rute dan jarak pengangkutan, kecepatan pengangkutan, dan waktu pengangkutan sampah serta densitas sampah di truk.

\section{METODE PENELITIAN}

\section{A. Penentuan Jumlah Truk Pengangkutan Sampah yang disurvei}

Truk pengangkutan sampah di Suurabaya Utara, disurvei untuk memperoleh data yang meliputi waktu pengangkutan sampah, jarak pengangkutan sampah, dan tonase sampah yang diangkut dari TPS ke TPA. Truk yang disurvei berjumlah 10 unit yang dipilih berdasarkan kategori umur teknis dan jarak TPS ke TPA yang dilayani. Daftar truk Daftar truk yang disurvei dapat dilihat Tabel 1. sebagai berikut. Truk dengan nomor polisi B9552EQ adala jenis Dum Truck dan selain yang disebutkan adalah jenis Arm Roll Truck.

Tabel 1.

Daftar Truk yang disurvei

\begin{tabular}{cccccc}
\hline \hline $\begin{array}{c}\text { No } \\
\cdot\end{array}$ & No.polisi & Instansi & $\begin{array}{c}\text { Tahun } \\
\text { Operasi }\end{array}$ & $\begin{array}{c}\text { Kapasitas } \\
\left(\mathbf{m}^{3}\right)\end{array}$ & $\begin{array}{c}\text { Jarak } \\
\text { TPS ke } \\
\text { TPA (km) }\end{array}$ \\
\hline 1 & L8063PP & DKP & 1995 & 8 & 18 \\
2 & L9001YP & DKP & 2007 & 8 & 20 \\
3 & L9487NP & DKP & 2014 & 8 & 25 \\
\hline \hline
\end{tabular}




\begin{tabular}{|c|c|c|c|c|c|}
\hline 4 & L8042RP & DKP & 1993 & 14 & 28 \\
\hline 5 & L8023SP & DKP & 2002 & 14 & 28 \\
\hline 6 & L8011SP & DKP & 2002 & 14 & 23 \\
\hline 7 & L9418NP & DKP & 2013 & 14 & 24 \\
\hline 8 & B9552EQ & DKP & 2013 & 14 & 17 \\
\hline 9 & $\begin{array}{c}\text { W } 8277 \\
\text { UP }\end{array}$ & $\begin{array}{c}\text { Rekana } \\
\mathrm{n}\end{array}$ & 2003 & 14 & 23 \\
\hline 10 & L 8977 UF & $\begin{array}{c}\text { Rekana } \\
\mathrm{n}\end{array}$ & 2013 & 14 & 21 \\
\hline
\end{tabular}

\section{B. Pengumpulan Data}

Pengumpulan data yang dilakukan meliputi pengumpulan data primer dan data sekunder. Data primer yang dibutuhkan meliputi waktu pengangkutan sampah dan jarak pengangkutan sampah. Pengumpulan data primer dilakukan dengan melakukan survei terhadap rute pengangkutan sampah yang dilakukan selama $2-3$ hari. Hari yang dipilih adalah hari kerja (hari senin sampai hari sabtu) dan hari libur (hari mingggu). Data sekunder yang dikumpulkan meliputi jumlah tonase sampah yang terangkut dari TPS ke TPA pada masing - masing truk, pola jumlah ritasi pengangkutan sampah setiap harinya, dan rute eksisting pengangkutan sampah. Pengumpulan data sekunder dilakukan dengan pencarian data eksisting ke Dinas Kebersihan dan Pertamanan (DKP) Kota Surabaya.

\section{HASIL DAN PEMBAHASAN}

\section{A. Analisis Sistem Pengangkutan Sampah dengan Arm Roll Truck}

Truk pengangkutan sampah dengan Arm Roll Truck di Surabaya Utara terdiri dari truk milik DKP dan truk milik rekanan, dari daftar truk yang disurvei terdiri dari 7 truk arm roll milik DKP dan 2 truk arm roll milik rekanan.

\section{1) Rute dan Jarak Pengangkutan}

Rute pengangkutan sampah menggunakan pola HCS (Hauled Container system) dimana penjelasan rute dengan HCS adalah sebagai berikut :

a. Truk dengan kontainer kosong bergerak dari pool ke TPS 1

b. Di TPS truk menurunkan kontainer kosong kemudian mengangkat kontainer isi di TPS

c. Truk dengan kontainer isi bergerak dari TPS menuju ke TPA

d. Di TPA truk melakukan unloading sampah di zona penimbunan

e. Truk dari TPA dengan kontainer kosong menuju ke TPS selanjutnya, jika melakukan ritasi lebih dari 1 kali

f. Ritasi diakhiri dengan truk dari TPA kembali menuju pool.

Pola rute pengangkutan sampah di Surabaya Utara dapat dilihat pada Gambar 1. Sebagai berikut :

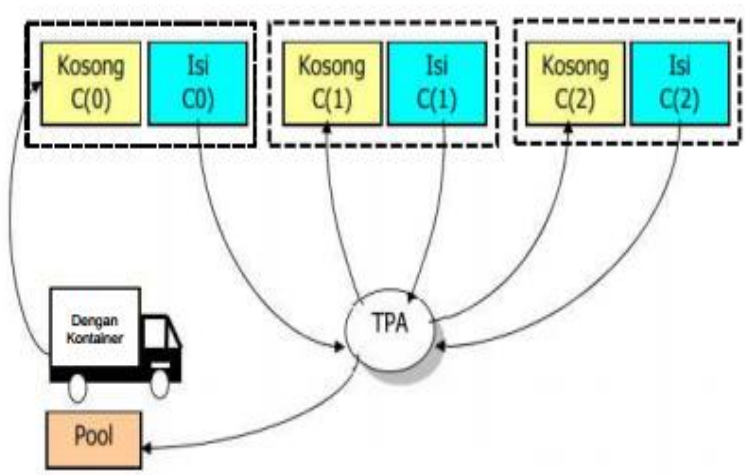

Gambar 1. Pola HCS Rute Pengangkutan Sampah

Alternatif jalan yang dipilih dalam operasional pengangkutan sampah di Surabaya Utara terdiri dari jalan biasa (nonhighways) dan melewati jalan tol (highways). Pemilihan alternatif jalan disesuaikan dengan kondisi kelancaran lalu lintas. Jarak pengangkutan sampah pada masing - masing truk ditentukan oleh pola jumlah ritasi setiap harinya dan jarak TPS yang dilayani ke TPA. semakin besar atau banyak jumlah ritasi yang dilakukan dan semakin jauh jarak TPS yang dilayani menuju ke TPA, maka total jarak pengangkutan setiapa harinya akan semakin besar. Total jarak pengangkutan sampah pada masing - masing truk yang disurvei dapat dilihat pada Tabel 2 . sebagai berikut.

Tabel 2.

Rata - Rata Total Jarak Pengangkutan

\begin{tabular}{cccc}
\hline No.polisi & $\begin{array}{c}\text { Pola } \\
\text { Ritasi }\end{array}$ & $\begin{array}{c}\text { Umur } \\
\text { Kendaraan }\end{array}$ & $\begin{array}{c}\text { Jarak } \\
(\mathbf{k m})\end{array}$ \\
\hline L8063PP & $2 \mathrm{x}, 1 \mathrm{x}$ & 1995 & 68,44 \\
L8042RP & $2 \mathrm{x}, 1 \mathrm{x}$ & 1993 & 86,32 \\
L8011SP & $2 \mathrm{x}, 2 \mathrm{x}$ & 2002 & 79,94 \\
L9001YP & $2 \mathrm{x}, 2 \mathrm{x}$ & 2007 & 84,37 \\
L8023SP & $2 \mathrm{x}, 2 \mathrm{x}$ & 2002 & 100,17 \\
L9418NP & $2 \mathrm{x}, 2 \mathrm{x}$ & 2013 & 102,17 \\
L9487NP & $2 \mathrm{x}, 2 \mathrm{x}$ & 2014 & 114,66 \\
W 8277 UP & $3 \mathrm{x}, 3 \mathrm{x}$ & 2003 & 147,80 \\
L 8977 UF & $3 \mathrm{x}, 3 \mathrm{x}$ & 2013 & 133,80 \\
\hline \hline
\end{tabular}

\section{2) Kecepatan Tempuh Pengangkutan Sampah}

Penelitian terhadap kecepatan pengangkutan sampah dilakukan dengan menggunakan aplikasi GPS yaitu my Tracks. Kecepatan yang terekamm meliputi kecepatan rata rata dan kecepatan maksimal pengangkutan sampah di Surabaya Utara. Kecepatan rata - rata pengangkutan sampah antara melewati jalan tol dan jalan biasa hampir sama dikarenakan patokan kecepatan rata - rata yang digunakan oleh truk sampah adalah sama. Kecepatan rata - rata yang digunakan oleh truk pengangkutan sampah adalah sekitar 20 $\mathrm{km} / \mathrm{jam}$. Umur teknis truk pengangkutan sampah tidak berpengaruh terhadap kecepatan tempuh pengangkutan sampah, namun kecepatan pengangkutan sampah dipengaruhi oleh kondisi kelancaran lalu lintas. 


\section{3) Waktu Pengangkutan Sampah}

Penelitian terhadap waktu pengangkutan sampah dilakukan dengan mencatat semua yang dikerjakan oleh Sopir truk. Survei dilakukan selama 2 sampai 3 hari yang terdiri dari hari kerja efektif dan hari libur. Satu hari kerja Sopir pengangkutan sampah DKP yaitu 9 jam yang terdiri dari 8 jam kerja efektif dan 1 jam istirahat. Jam kerja sopir truk rekanan lebih panjang karena jumlah ritasi per hari dari truk rekanan lebih banyak dari truk DKP yaitu $3-4$ rit/hari, sedangkan rata - rata ritasi truk DKP adalah 2 rit/hari. Waktu pengangangkutan sampah dipengaruhi oleh beberapa faktor meliputi jarak pengangkutan, alternatif jalan yang dilalui dan jumlah ritasi dalam satu hari. Perhitungan waktu pengangkutan sampah dapat dilakukan dengan pengelompokkan beberapa aktivitas pengangkutan yang dapat dilihat pada Tabel 3. berikut ini.

Tabel 3.

Pengelompokkan Waktu Pengangkutan Sampah

\begin{tabular}{|c|c|}
\hline $\begin{array}{c}\text { Aktivitas } \\
\text { t pengangkutan }\end{array}$ & Keterangan \\
\hline $\mathrm{t} 1$ & waktu dari pool ke TPS1 \\
\hline $\mathrm{t} 2$ & waktu dari TPA ke pool \\
\hline \multirow[t]{4}{*}{$\mathrm{pc}$} & waktu menaikkan kontainer di TPS \\
\hline & waktu tutup terpal kontainer di TPS \\
\hline & Watu menunggu kontainer penuh \\
\hline & waktu menunggu pengepressan sampah \\
\hline \multirow[t]{2}{*}{ uc } & waktu menurunkan kontainer di TPS \\
\hline & waktu memindahkan kontainer di TPS \\
\hline \multirow[t]{5}{*}{$\mathrm{s}$} & waktu penimbangan \\
\hline & waktu jalan di TPA \\
\hline & $\begin{array}{l}\text { waktu membuka kontainer } \\
\text { waktu unloading sampah di TPA }\end{array}$ \\
\hline & Waktu antri timbang \\
\hline & Waktu antri unloading \\
\hline \multirow[t]{2}{*}{$\mathrm{h}$} & waktu tempuh dari TPS ke TPA \\
\hline & waktu tempuh dari TPA ke TPS \\
\hline \multicolumn{2}{|l|}{ t operasional } \\
\hline & $\mathrm{t}$ mengambil surat jalan \\
\hline & antri mengisi BBM \\
\hline & mengisi BBM \\
\hline & Absen di pool \\
\hline \multirow[t]{5}{*}{ t offroute } & $\begin{array}{l}\text { waktu warming up dan memeriksa } \\
\text { kendaraan } \\
\text { Kemacetan }\end{array}$ \\
\hline & ban kempes \\
\hline & perbaikan lainnya \\
\hline & Gangguan lainnya \\
\hline & Nonproduktif \\
\hline $\begin{array}{l}\text { t sisa waktu } \\
\text { kerja }\end{array}$ & $\begin{array}{l}\text { menunggu menghabiskan jam kerja di } \\
\text { pool }\end{array}$ \\
\hline
\end{tabular}

Perhitungan faktor offroute pengangkutan sampah adalah sebagai berikut :

$$
W=w / H
$$

$W=$ faktor offroute, $w=$ waktu offroute (jam/hari), $H=$ jam kerja (jam/hari). Faktor offroute yang dihitung melalui persamaan (1) tidak boleh melebihi 0,15 [11]. Rata - rata pengelompokan waktu pengangkutan dapat diihat pada Tabel 4. di bawah ini.

Tabel 4.

Rata - Rata Waktu Pengangkutan pada Hari Kerja dan Hari Libur

\begin{tabular}{lcc}
\hline \hline $\begin{array}{l}\text { Rata - Rata } \\
\text { Pengunaan Waktu }\end{array}$ & $\begin{array}{c}\text { Hari } \\
\text { Efektif }\end{array}$ & $\begin{array}{c}\text { Hari } \\
\text { Libur }\end{array}$ \\
\hline $\begin{array}{l}\text { t pengangkutan } \\
\text { (jam/hari) }\end{array}$ & 3,83 & 3,41 \\
t operasional (jam/hari) & 0,05 & 0,08 \\
Faktor off route & 0,07 & 0,08 \\
Nd & 3 & 3 \\
\hline \hline
\end{tabular}

Semakin panjang jarak pengangkutan sampah semakin panjang pula waktu kerja atau aktivitas pengangkutan yang dibutuhkan. Faktor offroute rata - rata pengangkutan sampah $<0,15$, waktu offroute yang paling besar disebabkan oleh waktu memeriksa kendaraan pada pagi hari yang salah satunya adalah waktu memanaskan mobil. Penggunaan waktu pengangkutan pada hari efektif lebih banyak daripada hari libur namun tidak berbeda signifikan. Meskipun biasanya pada hari libur kondisi lalu lintas lebih lancar, namun hal ini tidak memberikan pengaruh yang besar pada waktu pengangkutan karena kecepatan rata - rata pengangkutan sampah antara hari biasa (efektif) dan hari libur hampir sama.

Rata - rata jumlah ritasi pengangkutan sampah adalah 2 rit/hari, sehingga waktu rata - rata yang digunakan untuk setiap kali ritasi dapat dilihat pada Tabel 5. sedangkan untuk waktu rata - rata yang dibutuhkan untuk melakukan aktivitas pengangkutan dapat dilihat pada Tabel 6 . sebagai berikut.

Tabel 5.

Waktu Rata - Rata Setiap Ritasi

\begin{tabular}{cccc}
\hline \hline $\begin{array}{c}\text { Nomor } \\
\text { Kendaraan }\end{array}$ & $\begin{array}{c}\text { jenis } \\
\text { kendaraan }\end{array}$ & $\begin{array}{c}\text { Tahun operasi } \\
\text { Kendaraan }\end{array}$ & $\begin{array}{c}\text { waktu rata - } \\
\text { rata (jam/ } \\
\text { ritasi) }\end{array}$ \\
\hline L8063PP & DKP & 1995 & 1,62 \\
L 8042 RP & DKP & 1993 & 2,48 \\
L 8011 SP & DKP & 2002 & 1,51 \\
L 9001 YP & DKP & 2007 & 1,57 \\
L 8023 SP & DKP & 2002 & 1,85 \\
L 9418 NP & DKP & 2013 & 2,34 \\
L 9487 NP & DKP & 2014 & 2,23 \\
W 8277 UP & rekanan & 2003 & 2,10 \\
L 8977 UF & rekanan & 2013 & 1,93 \\
\hline \hline
\end{tabular}


Tabel 6.

Waktu Rata - Rata Masing - Masing Aktivitas Pengangkutan Sampah

lalui sudah ditentukan

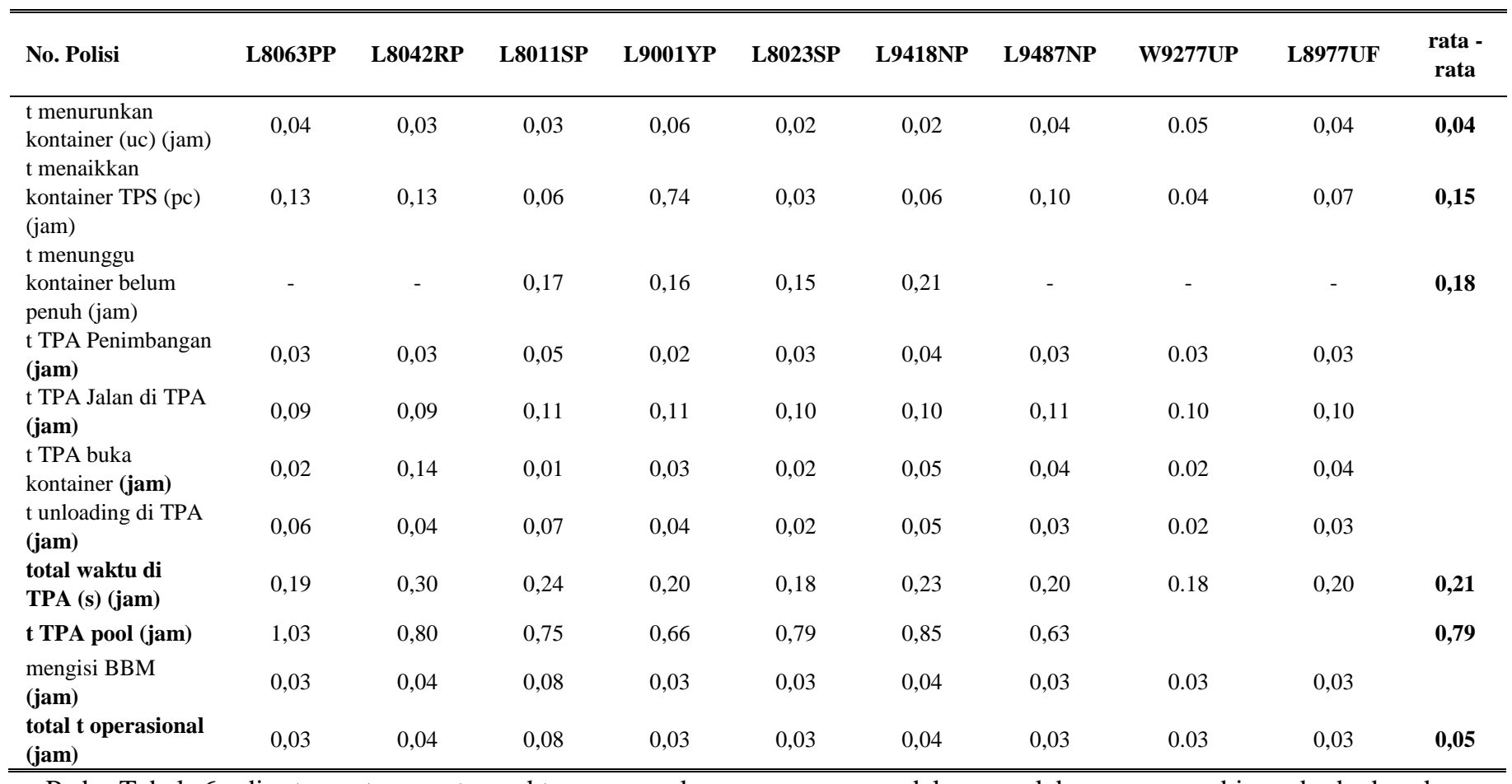

Pada Tabel 6. di atas rata - rata waktu menurunkan kontainer yaitu 0,04 jam dan rata - rata untuk menaikkan kontainer yaitu 0,15 jam. Waktu rata - rata TPS ke TPA ditentukan oleh jarak TPS ke TPA.

\section{B. Analisis Sistem Pengangkutan Sampah dengan Dump Truck}

Pengangkutan sampah oleh dump truck hanya melayani SPA (stasiun Peralihan Antara) Mbah Ratu.

\section{1) Rute dan Jarak Pengangkutan Sampah}

Rute pengangkutan sampah menggunakan pola SCS (Stationary Container system), Pola SCS pada Dump Truck yang melayani SPA Mbah Ratu mirip dengan HCS karena hanya dengan melayai satu lokasi TPS Dump Truck sudah penuh. Sistem loading sampah dilakukan dengan pengepressn sampah terlebih dahulu, setelah itu sampah yang sudah padat dan tercetak dimasukkan ke dalam kontainer Dump Truck. penjelasan rute Dump Truck adalah sebagai berikut :

a. Dump truck berangkat dari Pool Tanjung Sari menuju ke SPA Mbah Ratu dengan kontainer kosong

b. Di SPA sampah yang sudah dipress dimasukkan ke dalam kontainer

c. Dump truck menuju ke TPA dan melakukan pembuangan

d. Dump truck menuju ke SPA Mbah Ratu dengan kontainer kosong, di SPA sampah yang sudah dipress dimasukkan ke dalam kontainer

e. Dump truck menuju ke TPA kembali dan melakukan pembuangan

f. Dump truck menuju ke pool Tanjung Sari

Pengangkutan sampah oleh dump truck di Surabaya Utara melakukan 2 ritasi setiap harinya. Sama halnya dengan arm namun dalam pelaksanaannya bisa berbeda karena menyesuaikan kondisi jalan maupun kondisi kelancaran lalu lintas. Pada Tabel 7. berikut, dapat dilihat rute dan jarak tempuh eksisting dari Dump Truck.

Tabel 7.

Rute dan Jarak Eksisting Pengangkutan Sampah oleh Dump Truck

\begin{tabular}{|c|c|c|c|c|}
\hline \multirow{2}{*}{ No. Polisi } & \multirow{2}{*}{$\begin{array}{l}\text { Th. } \\
\text { Oper } \\
\text { asi }\end{array}$} & \multicolumn{2}{|c|}{ Rute yang ditenntukan } & \multirow{2}{*}{$\begin{array}{c}\text { Total } \\
\text { Jarak } \\
(\mathbf{k m} / \mathbf{h a r i})\end{array}$} \\
\hline & & Rute & Jenis Jalan & \\
\hline \multirow{5}{*}{ B9552EQ } & \multirow{5}{*}{2013} & $\begin{array}{c}\text { pool } \\
\text { Tanjungsari - } \\
\text { SPA Mbah } \\
\text { Ratu }\end{array}$ & $\begin{array}{c}\text { Jalan biasa (via } \\
\text { Jl. Dupak } \\
\text { Rukun) }\end{array}$ & \multirow{5}{*}{78,77} \\
\hline & & $\begin{array}{l}\text { SPA Mbah } \\
\text { Ratu - TPA }\end{array}$ & $\begin{array}{c}\text { Jalan biasa (via } \\
\text { Jl. Tambak } \\
\text { Osowilangun) }\end{array}$ & \\
\hline & & $\begin{array}{l}\text { TPA - SPA } \\
\text { Mbah Ratu }\end{array}$ & $\begin{array}{c}\text { Jalan biasa (via } \\
\text { Jl. Tambak } \\
\text { Osowilangun) }\end{array}$ & \\
\hline & & $\begin{array}{l}\text { SPA Mbah } \\
\text { Ratu - TPA }\end{array}$ & $\begin{array}{c}\text { Jalan biasa (via } \\
\text { Jl. Tambak } \\
\text { Osowilangun) }\end{array}$ & \\
\hline & & TPA - Pool & $\begin{array}{c}\text { Jalan biasa (Jl. } \\
\text { Margomulyo) }\end{array}$ & \\
\hline
\end{tabular}

Alternatif jalan tol biasanya dipilih untuk menempuh perjalanan dari SPA ke TPA. Sopir truk jarang menggunakan tol untuk meempuh dari TPA -Pool ataupun sebaliknya.

\section{2) Kecepatan Pengangkutan Sampah}

Kecepatan rata - rata pengangkutan sampah oleh dump truck pada hari efektif yaitu sekitar $24 \mathrm{~km} / \mathrm{jam}$ sedangkan pada hari libur sekitar $26 \mathrm{~m} / \mathrm{jam}$. Kecepatan penggangkutan 
sampah pada hari libur lebih besar daripada hari efektif namun tidak berbeda signifikan. Kecepatan rata - rata pada dump truck lebih besar dari arm roll truck dikarenakan kondisi kontainer dari dump truck yang tertutup rapat sehingga resiko sampah terkececer di jalan jika berkecepatan tinggi lebih kecil dari arm roll truck yang kebanyakan kontainernya ditutup dengan terpal.

\section{3) Waktu Pengangkutan Sampah}

Perhitungan waktu pengangkutan sampah pada dump truck adalah menggunakan SCS, namun karena di SPA terdapat mesin press, dan sampah yang diangkut dicetak sesuai ukuran kontainer sehingga dump truck ini hanya melayani SPA Mbah Ratu, sehingga perhitungan waktu pengangkutan pada dump truck juga dapat dilakukan dengan pengelompokkan terhadap aktivitas pengangkutan sampah sama seperti perhitungan waktu pengangkutan pada arm roll truck sesuai Tabel 3. di atas. Proses Ioading sampah ke dump truck tidak dilakukan dengan sistem kontainer angkat, sampah setelah melalui proses pengepresan, didorong oleh mesin press masuk kedalam kontainer dump truck, sehingga dalam pengangkutan sampah menggunakan dump truck tidak terdapat proses menurunkan kontainer (uc) dan tidak terdapat proses menaikkan kontainer (pc). Waktu pengangkutan sampah oleh dump truck dapat dilihat pada Tabel 8. di bawah ini.

Tabel 8.

Waktu Pengangkutan Sampah oleh Dump Truck

\begin{tabular}{lcc}
\hline \hline No. polisi & \multicolumn{2}{c}{ B9552EQ } \\
Hari & Efektif & Libur \\
Total t pengangkutan & 4,09 & 3,73 \\
(jam/hari) & 0,08 & 0,12 \\
Total t operasional (jam/hari) & 4,17 & 3,85 \\
T (jam/hari) & 0,86 & 1,89 \\
t1 + t2 & 0,79 & 0,27 \\
Total t off route (jam/hari) & 3,83 & 4,65 \\
t sisa jam kerja (jam/hari) & 0,1 & 0,03 \\
Faktor offroute & & \\
\hline \hline
\end{tabular}

Penggunaan waktu pengangkutan sampah antara hari libur dan dan hari efektif terjadi perbedaan yang cukup signifikan pada penggunaan waktu pengangkutan karena ketika survei pada hari efektif, truk melakukan 2 ritasi dalam satu hari, sedangkan pada hari libur melakukan satu kali ritasi saja. Menurut hasil survei, pada hari libur hanya dilakukan satu ritasi karena besarnya waktu menunggu pengepresan sampah yaitu sebesar 2,083 jam. Lamanya proses pengepresan diakibatkan oleh telatnya jadwal pengepresan dimulai, selain itu, dalam memasukkan sampah ke mesin press, sampah dari dari gerobak harus dibongkar satu per satu. Upaya untuk memperkecil waktu menunggu pada operasional pengangkutan sampah oleh dump truck di Surabaya Utara adalah dengan penjadwalan ulang jadwal pengepressan sampah dan jadwal pengambilan sampah di SPA Mbah Ratu untuk diangkut ke TPA.

\section{Timbulan dan Densitas Sampah di Truk Pengangkutan sampah}

Timbulan sampah yang terangkut dari TPS ke TPA penting untuk diketahui karena dapat dijadikan data sampah yang masuk ke TPA dan jumlah timbulan sampah dari TPS atau sampah rumah tangga yang dihasilkan di Surabaya Utara. Densitas sampah ditruk penting untuk diketahui karena dapat dijadikan data seberapa besar rata - rata truk mampu mengangkut muatan sampah.

\section{1) Timbulan Sampah yang Terangkut dan densitas Sampah pada Arm Roll truck}

Timbulan sampah yang diangkut oleh truk dapat diketahui dari hasil penimbangan pada jembatan timbang di TPA. Data hasil penimbangan direkap selama delapan hari berturut turut sehingga didapatkan rata - rata timbulan sampah yang diangkut dalam satuan $\mathrm{kg}$ / hari. Selain timbulan sampah dari TPS yang diangkut perhari, didapatkan juga data masa sampah pada setiap pengambilan di TPS. Timbulan sampah yang diangkut truk arm roll dan berat sampah per pengambilan di TPS Surabaya Utara dapat dilihat pada Tabel 9. di bawah ini dengan keterangan tulisan ynag diberi warna biru adalah truk milik rekanan.

Tabel 9.

Timbulan Sampah yang Terangkut ke TPA

\begin{tabular}{|c|c|c|c|}
\hline No. Polisi & $\begin{array}{c}\text { Kapasi } \\
\text { tas } \\
(\mathbf{m} 3)\end{array}$ & $\begin{array}{c}\text { Rata - } \\
\text { RataTimbulan yang } \\
\text { diangkut (kg/ hari) }\end{array}$ & $\begin{array}{c}\text { Rata - Rata } \\
\text { Timbulan Per } \\
\text { Pengambilan } \\
\text { (Kg/Rit) }\end{array}$ \\
\hline \multirow{2}{*}{ L 8063 PP } & \multirow{2}{*}{8} & 1881,25 & 1881,25 \\
\hline & & 215,00 & 1720,00 \\
\hline L 8042 RP & 14 & 9306,25 & 6768,18 \\
\hline L $8011 \mathrm{SP}$ & 14 & 5648,75 & 4519,00 \\
\hline L 9001 YP & 8 & 7121,25 & 4069,29 \\
\hline \multirow{2}{*}{ L 8023 SP } & \multirow{2}{*}{14} & 2958,75 & 3381,43 \\
\hline & & 3038,75 & 3038,75 \\
\hline \multirow{3}{*}{ L 9418 NP } & \multirow{3}{*}{14} & 7392,50 & 7392,50 \\
\hline & & 5370,00 & 5370,00 \\
\hline & & 4480,00 & 4480,00 \\
\hline \multirow[t]{2}{*}{ L 9487 NP } & \multirow[t]{2}{*}{8} & 3041,25 & 4055,00 \\
\hline & & 341,25 & 2730,00 \\
\hline W 8277 UP & 14 & 15597,50 & 5199,17 \\
\hline \multirow{2}{*}{ L 8977 UF } & \multirow{2}{*}{14} & 12002,50 & 4000,83 \\
\hline & & 20383,75 & 4076,75 \\
\hline
\end{tabular}

Densitas pada truk pengangkutan sampah dihitung dengan membandingkan rata - rata masa sampah yang diangkut setiap kali dengan volume sampah di dalam kontainer. 
Densitas pada arm roll truck dapat dilihat pada Tabel 10. di bawah ini.

Tabel 10.

Densitas Sampah di Arm Roll Truck

\begin{tabular}{ccccc}
\hline \hline $\begin{array}{c}\text { Nomor } \\
\text { Kendaraan }\end{array}$ & $\begin{array}{c}\text { Volume } \\
\text { Sampah di } \\
\text { Kontainer } \\
\mathbf{m}^{\mathbf{3}}\end{array}$ & $\begin{array}{c}\text { Kondisi } \\
\text { Kontainer }\end{array}$ & $\begin{array}{c}\text { Rata - Rata } \\
\text { Berat } \\
\text { Setiap } \\
\text { Pengambila } \\
\mathbf{n}(\mathbf{K g})\end{array}$ & $\begin{array}{c}\text { Densitas } \\
\text { Sampah } \\
\mathbf{d i} \text { Truk } \\
\left(\mathbf{K g} / \mathbf{m}^{3}\right)\end{array}$ \\
\hline L8063PP & 8 & Terbuka & 1881,25 & 235,16 \\
L 8042 RP & 8 & Terbuka & 1720,00 & 215,00 \\
L8011SP & 17 & Terbuka & 6768,18 & 398,13 \\
L 9001 YP & 14 & Terbuka & 4519,00 & 322,79 \\
& 10 & Terbuka & 4069,29 & 406,93 \\
L 8023 SP & 14 & tertutup & 3381,43 & 241,53 \\
& 14 & tertutup & 3038,75 & 217,05 \\
L 9418 NP & 17 & Terbuka & 7392,50 & 434,85 \\
& 14 & Terbuka & 5370,00 & 383,57 \\
L 9487 NP & 11 & Terbuka & 4480,00 & 407,27 \\
& 10 & Terbuka & 4055,00 & 405,50 \\
B 9552 EQ & 8 & Terbuka & 2730,00 & 341,25 \\
W 8277 UP & 14 & tertutup & 5525,33 & 394,67 \\
& 14 & Terbuka & 5199,17 & 371,37 \\
\hline \hline
\end{tabular}

Perhitungan densitas sampah di truk menunjukkan dengan kondisi kontainer yang masih ada tutupnya memiliki densitas yang lebih kecil daripada truk dengan bak kontainer terbuka. Rata - rata densitas sampah pada truk dengan kontainer tertutup yaitu $229,29 \mathrm{~kg} / \mathrm{m}^{3}$, sedangkan densitas rata - rata sampah pada truk dengan kontainer terbuka yaitu 361,85 $\mathrm{kg} / \mathrm{m}^{3}$. Truk yang mengalami kelebihan muatan adalah pada truk dengan nomor polisi L8042RP dan L9418NP dimana volume sampah di kontainer melebihi volume kontiner.

\section{2) Timbulan Sampah yang Terangkut dan densitas Sampah pada Dump Truck}

Satu kontainer drump truck rata - rata mampu menampung 30 gerobak per pengambilan. Rata - rata berat sampah yang terangkut oleh Dump Truck setiap kali ritasi yaitu $5525,33 \mathrm{~kg}$ / ritasi. Densitas rata - rata sampah di gerobak adalah 225 $\mathrm{kg} / \mathrm{m}^{3}$. Rata - rata volume sampah di gerobak adalah $1,3 \mathrm{~m}^{3}$, diperkirakan Berat rata - rata sampah yang dipres sebesar $8775 \mathrm{~kg}$, sehingga diperoleh kemampuan mesin press memadatkan sampah sebesar $626,76 \mathrm{~kg} / \mathrm{m}^{3}$.

Berat sampah yang tercatat di jembatan timbang lebih ringan karena saat proses pengepressan, terjadi kompaksi yang mengakibatkan lindi yang terkandung dalam sampah banyak yang keluar dan tidak ikut terangkut. Berat sampah dalam gerobak yang terangkut melalui SPA lebih besar daripada TPS dengan arm roll truck, namun biaya operasional dan pemeliharaan pada SPA lebih besar daripada TPS.

\section{KESIMPULAN}

Rata - rata total jarak pengangkutan $(\mathrm{km} / \mathrm{hari})$ pada arm roll truck ditentukan oleh jumlah ritasi dan jarak TPS yang dilayani menuju TPA. Jarak pengangkutan sampah pada dump truck sebesar 78,77 km/hari apabila melakukan 2 kali ritasi pada SPA Mbah Ratu. Kecepatan rata - rata pengangkutan sampah arm roll truck sekitar $20 \mathrm{~km} / \mathrm{jam}$ sedangkan pada dump truck sekitar $24 \mathrm{~km} / \mathrm{jam}$. Rata - rata faktor off route pada arm roll truck adalah 0,07 sedangkan pada dump truck adalah 0,01 . Faktor off route pengangkutan di Surabaya terhitung kecil, namun sisa waktu kerja yang banyak memungkinkan untuk dilakukan penambahan jumlah ritasi pengangkutan.

\section{UCAPAN TERIMA KASIH}

Penulis mengucapkan terimakasih kepada dosen pembimbing dan dosen penguji Tugas Akhir atas saran dan masukan terhadap penulisan jurnal serta kepada Kementerian Ristek dan Dikti atas beasiswa Bidikmisi angkatan 2012 yang telah mensupport penulis selama masa perkuliahan serta kepada penelitian dosen yang telah memberikan biaya untuk peneitian tugas akhir penulis.

\section{DAFTAR PUSTAKA}

[1] Y. Dhokhikah dan Y. Trihadiningrum. 2012. Solid waste management in Asian developing countries: Challenges dan opportunities. Journal ofApplied Environmental dan Biological Science, 2 (7), 329-335.

[2] Y. Dhokhikah, Y. Trihadiningrum, dan S. Sunaryo. 2015. Community participation in household solid waste reduction in Surabaya, Indonesia. Resources, Conservation dan Recycling, 102, 153-162.

[3] Dinas Kebersihan dan Pertamanan Kota Surabaya. 2013. Jumlah TPS/Depo Kota Surabaya. Surabaya.

[4] Pemerintah Republik Indonesia. 2008. Undang-Undang Republik Indonesia Nomor 18 Tahun 2008 Tentang Pengelolaan Sampah.

[5] G. MacRae dan L. Rodic. 2015. The weak link in waste management in tropical Asia? Solid waste collection in Bali. Habitat International, $50,310-316$.

[6] Z. Zsigraiova, V. Semiao, dan F. Beijoco. 2013. Operation costs dan pollutant emissions reduction by definition of new collection scheduling dan optimization of MSW collection routes using GIS. The case study of Barreiro, Portugal. Waste Management, 33 (4), 793806.

[7] Badan Pusat Statistik Kota Surabaya. 2015. Surabaya dalam Angka 2014. Surabaya.

[8] Pemerintah Republik Indonesia. 2013. Peraturan Menteri Pekerjaan Umum Republik Indonesia Nomor 03/PRT/M/2013 Tentang Penyelenggaraan Prasarana dan Sarana Persampahan Dalam Penanganan Sampah Rumah Tangga dan Sampah Sejenis Sampah Rumah Tangga. Jakarta.

[9] Dinas Kebersihan dan Pertamanan Kota Surabaya. 2014. Jumlah TPS/Depo Kota Surabaya. Surabaya.

[10] G. Tchobanoglous, H. Theisen, Vigil, Samuel. 1993. Integrated Solid Waste Management : Engineering Principles Dan Issues. McGraw Hill International Editions. 